\title{
Selective Blockage of the Catalyst Active Sites for the Hydrogenation of Various Functional Groups over Raney Nickel and Nickel Supported on Silica
}

\section{Andrei V Afineevskiii, Tatiana Y Osadchaia, Dmitrii A Prozorov and Mikhaill V Lukin}

\begin{abstract}
Institute of Thermodynamics and Kinetics of Chemical Processes, Ivanovo State University of Chemistry and Technology, Ivanovo, Pr F Engelsa 7, 153000, Russia
\end{abstract}

\section{Corresponding author: \\ Andrei V Afineevskii \\ = afineevskiy@mail.ru \\ Institute of Thermodynamics and Kinetics of Chemical Processes, Ivanovo State University of Chemistry and Technology, Ivanovo, Pr F Engelsa 7, 153000 Russia.}

Tel: 7-920-6727145

Citation: Afineevskii AV, Osadchaia TY, Prozorov DA, et al. Selective Blockage of the Catalyst Active Sites for the Hydrogenation of Various Functional Groups over Raney Nickel and Nickel Supported on Silica. Trends Green Chem. 2016, 2:1.

have low toxicity, but metallic nickel has lower activity than noble metal catalysts [8-10].

Despite long history of Raney nickel it is still actively studied and applied in the industry [11-16]. The nickel has a number of well-known advantages: high activity and selectivity and disadvantages: low stability and life time [17-19].

For this investigation Raney nickel was selected as the catalyst, because it is reproducible and well-studied, it is convenient to use as a model of a nickel catalyst, since many properties similar to other kinds of nickel hydrogenation catalysts [18].

However, it was taken nickel inflicted on silica $\mathrm{Ni} / \mathrm{SiO}_{2}$, prepared according to a specially developed method, by direct reduction of a precursor consisted from a mixture of $\mathrm{NiO}$ and $\mathrm{Ni}_{2} \mathrm{O}_{3}$ supported on silica, to account for the influence of the media.

There is hydrogenation step to receive a number of substances, such as $\mathrm{p}$-aminobenzoic acid, $\mathrm{m}$-aminobenzoic acid, sulfanilamide, 
2,5-dichloro-3-aminobenzoic acid, p-toluidine, adrenalon, sarcolysine, sorbitol, $\mathrm{p}$-aminophenyl allyl ether, $\mathrm{p}$-chloroaniline. Such substances are very important in various fields, particularly in medicine, thus for medical use the obtaining of highly pure product becomes critically important. However, the above substances are obtained with a number of byproducts. One of the reasons for the large number of by-products is the presence of several hydrogenation-sensitive substituents [20-23].

It is known all heterogeneous catalysts have nonuniform surface that contains different surface active sites and different type of energy adsorption bond [24,25]. A detailed review article published by Hochard and Renouprez [26] deals with the problems of different hydrogen species on Raney Nickel. Basically, the methods of TPD, adsorption calorimetry, potentiometry, spectroscopy, quantum chemistry calculations and XPS were found forms of hydrogen on $\mathrm{Ni}[24,25,27-31]$. The first state of the adsorbed hydrogen is $\mathrm{M}-\mathrm{H}_{2}$ - loosely coupled $\alpha_{2}$-form of molecular hydrogen with linear structure. Area of hydrogen desorption from the nickel is in the range 193-293 $\mathrm{K}$ [30]. The second state of $\mathrm{M}-\mathrm{H}^{2 \delta+}$ is $\alpha_{1}$-molecular form of hydrogen, but the bridge structure. Area of hydrogen desorption from the nickel is in the range 293-393K [28,31]. The third form is medium coupled $\mathrm{\gamma}$-form $\left(\mathrm{M}-\mathrm{H}^{2 \delta+}\right)$. For all transition metals are characterized by a wide area of hydrogen desorption $\mathrm{M}-\mathrm{H}^{28+}$ from 393 to $658 \mathrm{~K}$ $[25,31]$. Form $\mathrm{M}-\mathrm{H}^{2 \delta-}$ is atomic most strongly associated with the surface of transition metals $\beta_{2}$-form. This type of chemisorption is a kind of dissolution, when the hydrogen atom is located on the $0,5 \AA$ under electronic metal surface inside the lattice. Area of desorption is in the range 673-1173 $\mathrm{K}$ [32]. It was found that on the surface of the Raney Nickel hydrogen is adsorbed in three forms: two-centred molecular $\alpha_{1}$-form, single-centred atomic $\gamma$ and multi-centred $\beta_{2}$-form [29,31].

Thus for the selective reduction of a chosen functional group it becomes important that these sites have different activity for the hydrogenation of the different groups. In this case, it is apparent that the blocking of certain active sites will allow changing the selectivity of the hydrogenation of the chosen functional group. Sodium sulphide was chosen as an agent that is capable to block such sites because sulphur compounds, including sulphide ion, are the most studied catalytic poisons, that are blocking the active sites of the catalyst surface, and lower the activity of the catalysts for hydrogenation reactions [33-35]. In this case, the degree of deactivation is convenient to characterize by the initial amount of the entered sodium sulphide per gram of nickel, or as a part of the value of a certain amount of poison $[33,36]$.

The aim of this work was to determine the possibility of purposeful blocking of certain catalyst active sites, which are the most active in certain reactions to change the selectivity of the catalyst. With the ultimate goal should be to develop a method for producing high-efficiency catalytic system for hydrogenation of multiple bonds "carbon-carbon" and of a nitro group. The investigation of highefficiency catalytic systems based on supported nickel and Raney nickel for synthesis of compounds with few hydrogenation-sensitive substituents, such as in the preparation of 4-aminophenyl allyl ether, which is an enzyme inhibitor.

\section{Experimental}

\section{Catalysts}

We used a Raney nickel catalyst (hereinafter $\mathrm{Ni}_{\text {skel }}$ ), received by treatment of a nickel-aluminium alloy by sodium hydroxide according to known method [37]. The nickel catalyst prepared by this method had such characteristics: specific surface area (BET) is $170 \pm 5 \mathrm{~m}^{2} \cdot \mathrm{g}^{-1}$, porosity is $0.5 \pm 0.05$, size pore radius is $2 \mathrm{~nm}$.

Also nickel on silica (hereinafter $\mathrm{Ni} / \mathrm{SiO}_{2}$ ) was used. "Silica $\mathrm{L} 5 / 40$ $\mathrm{m}$ " was used for the synthesis as support. The average particle radius of silica is $5 \mu \mathrm{m}$, the specific surface is $276 \pm 5 \mathrm{~m}^{2} \cdot \mathrm{g}^{-1}$.

The synthesis of supported catalysts had the steps: preparing support, impregnating by an aqueous $2 \mathrm{M}$ solution of nickel nitrate, drying and recovery of nickel oxides. The support was impregnated once with constant stirring at $5 \mathrm{~Hz}$ and the ratio of the support to solution is 1 to 15 . The impregnation time was 4 hours at a temperature of $30^{\circ} \mathrm{C}$. The impregnated support was separated from the solution by a glass filter. Further drying was carried out at $\mathrm{t}=80^{\circ} \mathrm{C}$ till receiving supported crystalline hydrates. Then, thermal decomposition of crystalline hydrates was carried out. The crude product was placed into a furnace and heated at $t$ $=470^{\circ} \mathrm{C}$ for $2 \mathrm{~h} . \pm 30 \mathrm{~min}$. So obtained crude product was placed into a tube furnace and reduced in a hydrogen flow (hydrogen flow rate is $2.10 \mathrm{~cm}^{3} \cdot \mathrm{min}^{-1}$.) at $\mathrm{t}=450^{\circ} \mathrm{C}$ until no $\mathrm{H}_{2} \mathrm{O}$ ( 2 hours. \pm $10 \mathrm{~min}$.$) .$

\section{Equipment and methods}

The distribution of particle size of a catalyst powder was checked by a laser granulometer Analysette 22 Compact by Fritsch. The specific surface area was determined by means hardware complex "Flowsorb II 2300", via the low-temperature nitrogen adsorption by a BET method.

Solutions of sodium sulphide in the chosen solvent for the deactivation were used. Direct potentiometric method was used to determine the concentration of $\mathrm{S}_{2}$ - ions in the solution. Deactivation of the catalyst was carried out by the method described in [36].

Kinetic studies of the reaction liquid phase hydrogenation were carried out by a static method at nonstationary conditions in a pressurized liquid reactor with intense stirring of the reaction mass at atmospheric hydrogen pressure $[17,36]$. In all experiments, the weight of active metal was $0.25-0.5 \mathrm{~g}$, the activity of the catalyst was calculated by hydrogenation rate of model compound at less than 0.05 from conversion level.

The characterization of poisoning behaviour (selectivity of deactivation) was carried out by the Bartholomew's method [35]. The one is based on the analysis of the kinetic parameters of the process and is specially modified for the use in the liquid phase hydrogenation, the essence of which is the determination of preferential adsorption of deactivating agent on the certain atomic ensembles of the surface.

Diagram illustrating such analysis of poisoning behaviour is shown in Figure 1, where the activity of the catalyst $A$ and the quantity of poison $\mathrm{C}$ are normalized via [35]: 
$A=r_{0, c} / r_{0, C=0}$

$\mathrm{C}=\mathrm{n}_{\mathrm{i}} / \mathrm{n}_{\max }$

Where $r_{0, c}$ and $r_{0, c=0}$ are the initial hydrogenation reaction rates in the solvent (activity) of deactivated catalysts and nondeactivated, respectively; $n_{i}$ is quantity of the added catalyst poison per gram of catalyst; $n_{\text {max }}$ is the added quantity of catalyst poison per gram of catalyst, wherein the catalyst completely loses its activity. The dependence of the activity vs poison concentration shown in Figure 1 is based on the assumption of a homogeneous poisoning of catalyst surface and reaction surface, i.e. at insignificant diffusion resistance of pores.

"Selective" poisoning involves preferential adsorption of the poison on the most active sites at low concentrations. If sites of lesser activity are blocked initially, the poisoning is "antiselective". If the activity loss is proportional to the concentration of adsorbed poison, the poisoning is "non-selective" [35].

\section{Results and Discussion}

Basic physical and chemical parameters of catalysts investigated for the article are presented in Table 1.

According to Table 1, the catalytic activity of the supported nickel catalyst is more than 2 times higher than traditional Raney nickel for the reduction reactions of multiple bonds in the molecule of sodium maleate. While the supported catalyst has a lower specific surface for the same catalyst particle radius. Obviously, this fact should be explained by different ratios of the active metal on the surface involved in the reaction to the bulk metal mass. Thus, the contradiction is only apparent and should be eliminated by the appropriate experimental data processing.

Figure $2 \mathrm{a}$ shows the dependences of the observed rate of the reaction of sodium maleate hydrogenation over $\mathrm{Ni} / \mathrm{SiO}_{2}$ in an aqueous medium and at presence of the catalyst poison (sodium

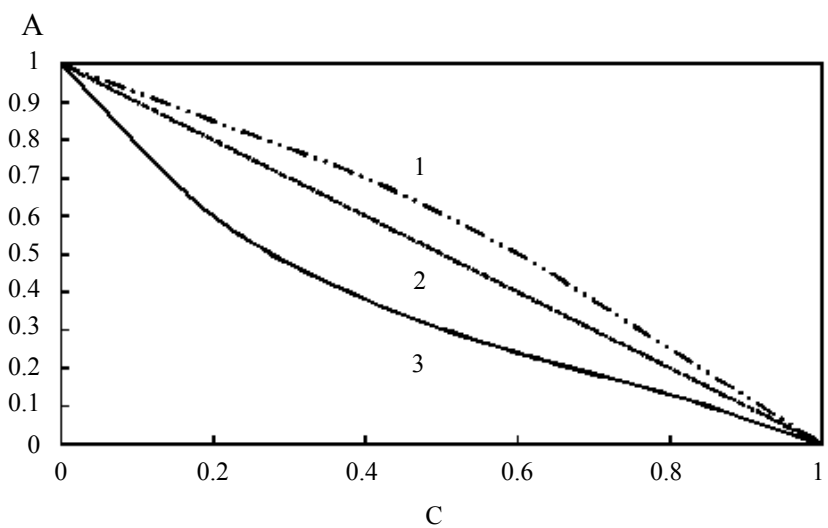

Figure 1 Three kinds of poisoning behavior: 1) antiselective poisoning; 2) non-selective poisoning; 3) selective poisoning [35]

Table 1 Properties of the catalyst samples.

\begin{tabular}{|c|c|c|c|c|}
\hline Catalyst & $\omega(\mathrm{Ni}), \%$ & $\mathrm{~S}_{\text {specific }} \mathrm{m}^{2} / \mathrm{g}$ & $r \phi, \mu m$ & $A^{*}$ \\
\hline $\mathrm{Ni}_{\text {skel }}$ & $88.3 \pm 0.5$ & $170 \pm 5$ & $4.8 \pm 0.1$ & $250 \pm 10$ \\
\hline $\mathrm{Ni} / \mathrm{SiO}_{2}$ & $11.0 \pm 0.3$ & $71 \pm 5$ & $5 \pm 0.1$ & $580 \pm 30$ \\
\hline
\end{tabular}

* Activity according to [36], $\mathrm{cm}^{3}\left(\mathrm{H}_{2}\right) \cdot \mathrm{g}^{-1}(\mathrm{Ni}) \cdot \mathrm{min}^{-1}$

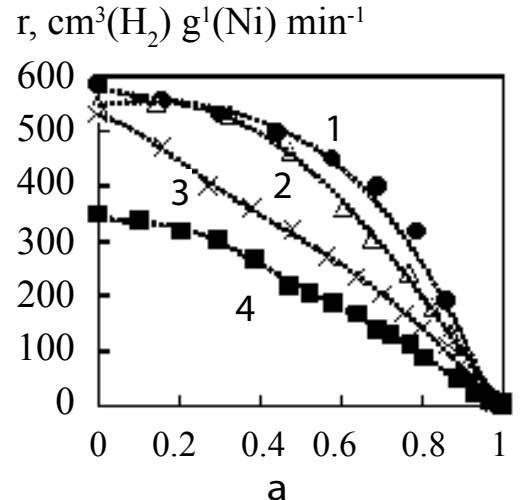

Figure 2a The dependence of the observed rate for reaction of sodium maleate hydrogenation over $\mathrm{Ni} / \mathrm{SiO}_{2}$ from conversion level, with different quantity of the added sulphide ion per gram of metal: $1-0 ; 2-0.12$; 3-0.24; 4-0.36 mmol ( $\left.\mathrm{Na}_{2} \mathrm{~S}\right) / \mathrm{g}(\mathrm{Ni})$. Reaction conditions: $\mathrm{T}=303 \mathrm{~K} ; \mathrm{P}=$ $0.1 \mathrm{MPa}$; medium: distilled water.

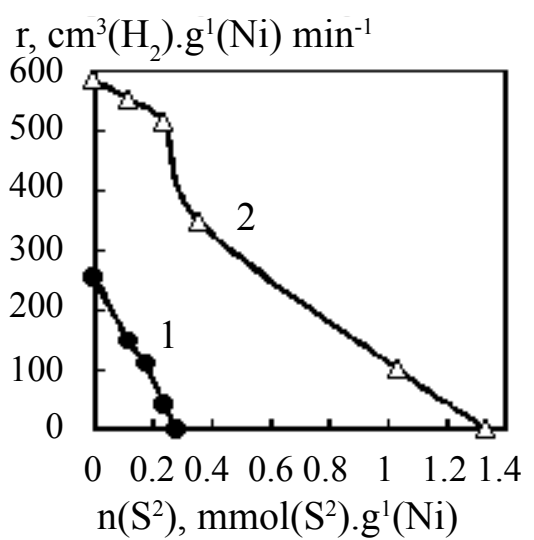

Figure 2b Catalytic activities for the hydrogenation reaction of sodium maleate over 1) Raney nickel and 2) $\mathrm{Ni} / \mathrm{SiO}_{2}$, from the entered quantity of sodium sulphide per gram of the metal. Reaction conditions: $\mathrm{T}=303 \mathrm{~K} ; \mathrm{P}=0.1 \mathrm{MPa}$; medium: distilled water.

sulphide) vs conversion level. Figure $\mathbf{2} \mathbf{b}$ shows the dependences of the activity (initial rate from Figure $\mathbf{2 a}$ ) of the catalyst for the hydrogenation of sodium maleate from the added quantity of catalyst poison. Figure $\mathbf{2} \mathbf{b}$ shows the absolute values to assess the stability of the catalyst to its sulphide poisoning, and Figure $\mathbf{2 c}$ in relative terms, that allows to judge the nature of this deactivation via Bartholomew's method, i.e. the selectivity of blocking the active sites of the catalyst.

According to the experimental data, we can reasonably say that resistance to deactivation of supported nickel at low concentrations of sulphide ion is higher because decrease of catalytic activity for Raney nickel with $0.24 \mathrm{mmol}$ of sodium 


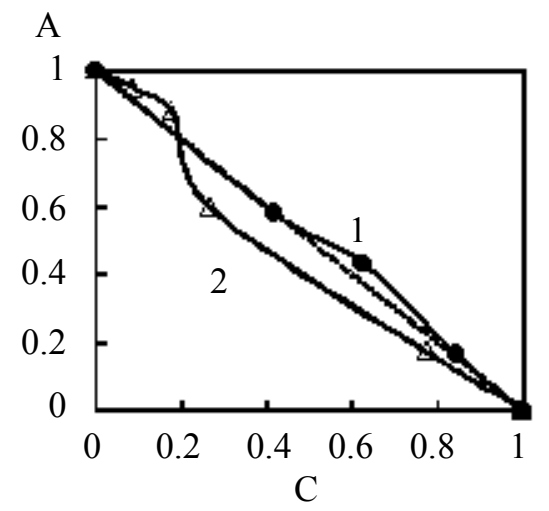

Figure 2c The normalized activities of the catalyst for the hydrogenation reaction of sodium maleate over 1 ) Raney nickel and 2) $\mathrm{Ni} / \mathrm{SiO}_{2}$, from the normalized quantity the added sodium sulphide per gram of nickel. Reaction conditions: $\mathrm{T}=303 \mathrm{~K} ; \mathrm{P}=$ $0.1 \mathrm{MPa}$; medium: distilled water.

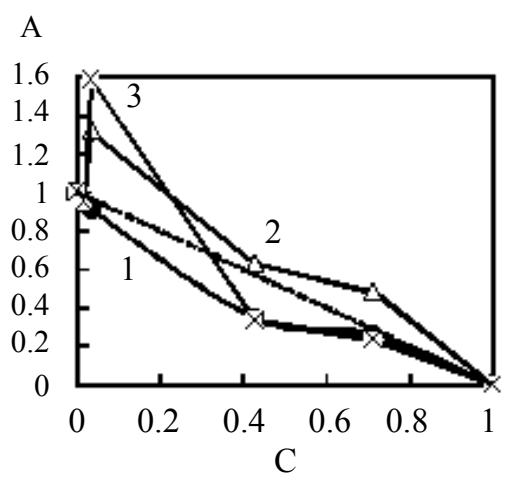

Figure 2d The dependence of normalized activity vs normalized poison concentration for hydrogenation of MADE in solution:

1. $\mathrm{H} 2 \mathrm{O}-\mathrm{i}-\mathrm{PrOH} 0.073$ mole fraction:

2. $\mathrm{H} 2 \mathrm{O}$ - i-PrOH 0.191 mole fraction;

3. $\mathrm{H} 2 \mathrm{O}-\mathrm{i}-\mathrm{PrOH} 0.68$ mole fraction.

sulphide addition per gram of nickel was $84 \%$, while it was just $12 \%$ supported one.

Such a difference in the rate of deactivation can be explained by the fact that a part of atoms of the catalyst poison can be adsorbed not only by the nickel but also by the support $\left(\mathrm{SiO}_{2}\right)$. A further sharp decrease in activity was due to the blocking of support pores by sulphide ion.

Figures $\mathbf{2} \mathbf{d}-\mathbf{2} \mathbf{f}$ show graphs similar to $2 \mathrm{c}$, but with additives in a solvent to demonstrate the effect from solvent to the behaviour of the catalyst poisoning.
According to Figure $2 \mathrm{c} \mathrm{Ni}_{\text {skel }}$ at the experimental conditions shows a non-selective behaviour of poisoning, but $\mathrm{Ni} / \mathrm{SiO}_{2}$ shows mixed behaviour of deactivation, i.e. the combined surface (surface of the nickel structures, of the $\mathrm{SiO}_{2}$ structures and of their combination) gives a more complex picture of $\mathrm{Ni} / \mathrm{SiO}_{2}$ poisoning than $\mathrm{Ni}_{\text {skel }}$. Therefore, using acidic or basic support even in neutral media it is possible to change the selectivity of nickel deactivation, which leads to the possibility of creating highly selective catalytic systems.

In the Table $\mathbf{2}$ are depicted the hydrogenation reactions sodium maleate and sodium p-nitrophenoxide in alkali media. Maleic acid diethyl ester and p-Nitrotoluene was used in alcohol solution.

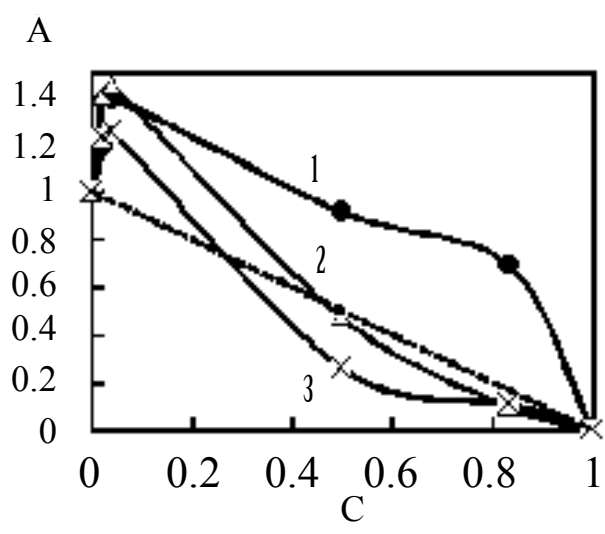

Figure $\mathbf{2} \mathbf{e}$ The dependence of normalized activity vs normalized poison concentration for hydrogenation of 4-Nitrotoluene in solution:

1. $\mathrm{H}_{2} \mathrm{O}-\mathrm{i}-\mathrm{PrOH} 0.073$ mole fraction;

2. $\mathrm{H}_{2} \mathrm{O}$ - i-PrOH 0.191 mole fraction;

3. $\mathrm{H}_{2} \mathrm{O}-\mathrm{i}-\mathrm{PrOH} 0.68$ mole fraction.

A

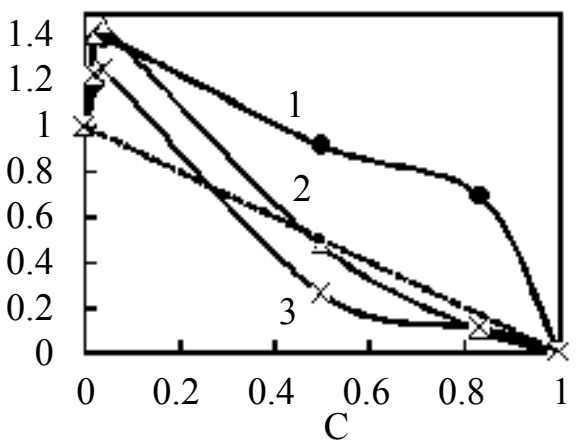

Figure $2 \mathbf{f}$ The dependence of normalized activity vs normalized poison concentration for hydrogenation of NaPNP in solution:
1. $\mathrm{H}_{2} \mathrm{O}-\mathrm{NaOH} 0.01 \mathrm{M}$;
2. $\mathrm{H}_{2} \mathrm{O}-\mathrm{NaOH} 0.1 \mathrm{M}$. 
Table 2 The hydrogenation reactions.

MaDE - Maleic acid diethyl ester

Table 3 Summarized information from figures number 2 of media influence.

\begin{tabular}{|c|c|c|}
\hline $\mathrm{H}_{2} \mathrm{O}-\mathrm{NaOH} 0.01 \mathrm{M}$ & $>\mathrm{C}=\mathrm{C}<$ & $-\mathrm{NO}_{2}$ \\
\hline $\mathrm{H}_{2} \mathrm{O}-\mathrm{NaOH} 0.1 \mathrm{M}$ & Selective $^{\mathrm{a}}$ & Mixture $^{\mathrm{b}}$ \\
\hline $\mathrm{H}_{2} \mathrm{O}-\mathrm{NaOH} 1 \mathrm{M}$ & Non-selective $^{\mathrm{a}}$ & Selective $^{\mathrm{b}}$ \\
\hline $\mathrm{H}_{2} \mathrm{O}-\mathrm{i}-\mathrm{PrOH}\left(0.073^{* *}\right)$ & Selective $^{\mathrm{c}}$ & - \\
\hline $\mathrm{H}_{2} \mathrm{O}-\mathrm{i}-\mathrm{PrOH}\left(0.191^{* *}\right)$ & Antiselective $^{c}$ & Antiselective $^{\mathrm{d}}$ \\
\hline $\mathrm{H}_{2} \mathrm{O}-\mathrm{i}-\mathrm{PrOH}\left(0.68^{* *}\right)$ & Mixture $^{c}$ & Mixture $^{\mathrm{d}}$ \\
\hline
\end{tabular}

*Media for carry out of reaction

$* *$ mole fraction

abcd The kind of poisoning behavior to NaMal (a) or to NaPNP (b) or to MADE (c) or to 4-Nitrotoluene (d)

where $\mathrm{i}-\mathrm{PrOH}$ is 2-Propanol.

This was chosen due to their solubility.

Summarized information about the character of deactivation behavior while using compounds with different functional groups represented in Table 3.

\section{Conclusions}

When experiments to determine the behaviour of deactivation by the method proposed Bartholomew [35] for the gas phase and modified by us for the liquid phase were carried out, the reactants with different hydrogenation-sensitive substituents were used. If reactants were hydrogenated by the same active surface sites, then the behaviour of deactivation would be the same for the different reactants. Table 3 shows that by using a reactants with different hydrogenation-sensitive substituents the behavior of deactivation in the same condition was different. This means that different active sites are involved in the hydrogenation of different functional groups. As well, it can be concluded that the sulphide is able to selectively remove from the reaction zone the certain active sites. This fact allow us to create a catalytic system with defined active sites, which able to a selectively hydrogenate chosen functional group. For example, if we have substance with $>\mathrm{C}=\mathrm{C}<$ and $-\mathrm{NO}_{2}$ group, but it is need to hydrogenate predominantly $>\mathrm{C}=\mathrm{C}<$ to $\equiv \mathrm{C}-\mathrm{C} \equiv$ and left $-\mathrm{NO}_{2}$ as it is, then $\mathrm{H}_{2} \mathrm{O}-\mathrm{NaOH} 0.1 \mathrm{M}$ media is a preferred; and opposite for hydrogenate $-\mathrm{NO}_{2}$ to $-\mathrm{NH}_{2}$ and left $>\mathrm{C}=\mathrm{C}<$ as it is, then $\mathrm{H} 2 \mathrm{O}$ $-\mathrm{i}-\mathrm{PrOH}$ ( 0.073 mole fraction) media is a preferred. Thereby it is need to choose a system with a maximum difference in the Bartholomew Curves.

That number of identified regularities gives a theoretical basis for the fine adjustment of quantity of different active sites on the catalyst surface and for purposeful change of a nickel catalyst activity in a selected reaction.

\section{Acknowledgement}

The practical part of the work was carried out as part of the State task (project 1800).

The theoretical part of the work is supported by the Russian Ministry of Education and Science (project №4.1385.2014/K)

Work is executed at the Institute of Thermodynamics and kinetics of chemical laboratories processes "Ivanovo State University of Chemistry and Technology". 


\section{References}

1 Huang Y, Chen X, Deng Y, Zhou D, Wang L (2015) A novel nickel catalyst derived from layered double hydroxides (LDHs) supported on fluid catalytic cracking catalyst residue (FC3R) for rosin hydrogenation. Journal Chem Eng 269: 434-443.

2 Boldrini DE, Tonetto GM, Damiani DE (2015) Experimental study of the deactivation of $\mathrm{Pd}$ on anodized aluminum monoliths during the partial hydrogenation of vegetable oil. Journal Chem Eng 270: 378-384.

3 Pérez D, Olivera-Fuentes $C$, Curbelo S, Rodríguez MJ, Zeppieri S (2015) Study of the selective hydrogenation of 1, 3-butadiene in three types of industrial reactors. Fuel 149: 34-45.

4 Liu CY, Wei RP, Geng GL, Zhou MH, Gao LJ, et al. (2015) Aqueousphase catalytic hydrogenation of furfural over Ni-bearing hierarchical Y zeolite catalysts synthesized by a facile route. Fuel Process Technol 134: 168-174

5 Rover MR, Hall PH, Johnston PA, Smith RG, Brown RC (2015) Stabilization of bio-oils using low temperature, low pressure hydrogenation. Fuel Process Technol 153: 224-230.

6 Wang H, Rempel GL (2015) Aqueous-phase catalytic hydrogenation of unsaturated polymers. Catal Today 247: 117-123.

7 Zhaobang S (1995) Production and standards for chemical non-wood forest products in China. CIFOR 6: 1-18.

8 Van de Vyver S, Geboers J, Schutyser W, Dusselier M, Eloy P, et al. (2012) Tuning the Acid/Metal Balance of Carbon NanofiberSupported Nickel Catalysts for Hydrolytic Hydrogenation of Cellulose. Chem Sus Chem 5: 1549-1558.

9 Wu YG, Wen M, Wu QS, Fang H (2014) Ni/graphene nanostructure and its electron-enhanced catalytic action for hydrogenation reaction of nitrophenol. J Phys Chem C 118: 6307-6313.

10 Donphai W, Kamegawa T, Chareonpanich M, Yamashita H (2014) Reactivity of Ni-Carbon Nanofibers/Mesocellular Silica Composite Catalyst for Phenylacetylene Hydrogenation. Ind Eng Chem Res 53: 10105-10111.

11 Raney M (1925) US Patent 1,563,787.

12 Raney M (1927) US Patent 1,628,191.

13 Fow KL, Ganapathi M, Stassen I, Binnemans K, Fransaer J, et al. (2015) Catalytically active gauze-supported skeletal nickel prepared from $\mathrm{Ni}-\mathrm{Zn}$ alloys electrodeposited from an acetamide-dimethyl sulfone eutectic mixture. Catal Today 246: 191-197.

14 Hoffer BW, Crezee E, Devred F, Mooijman PRM, Sloof WG, et al. (2003) The role of the active phase of Raney-type Ni catalysts in the selective hydrogenation of D-glucose to D-sorbitol. Appl Catal A 253 : 437-452.

15 Hu H, Qiao M, Wang S, Fan K, Li H, et al. (2004) Structural and catalytic properties of skeletal $\mathrm{Ni}$ catalyst prepared from the rapidly quenched Ni 50 Al 50 alloy. J Catal 221: 612-618.

16 Chade D, Berlouis L, Infield D, Cruden A, Nielsen PT, et al. (2013) Evaluation of Raney nickel electrodes prepared by atmospheric plasma spraying for alkaline water electrolysers. Int J Hydrogen 38: 14380-14390.

17 Lukin MV, Afineevskii AV (2015) Effect of additions of sodium hydroxide on the catalytic activity of partially deactivated skeletal nickel in reactions of the liquid-phase hydrogenation of sodium maleate in aqueous-organic media. Russ J Phys Chem A 89: 1173-1177.

18 Van Haasterecht T, Ludding CCI, De Jong KP, Bitter JH (2014) Toward stable nickel catalysts for aqueous phase reforming of biomassderived feedstock under reducing and alkaline conditions. J Catal 319: 27-35.

19 Shabaker JW, Huber GW, Dumesic JA (2004) Aqueous-phase reforming of oxygenated hydrocarbons over Sn-modified $\mathrm{Ni}$ catalysts. J Catal 222: 180-191.

20 US patent $3853935 \mathrm{~A}$.

21 Koklin AE, Klimenko TA, Kondratyuk AV, Lunin VV, Bogdan VI (2015) Transformation of aqueous solutions of glucose over the $\mathrm{Pt} / \mathrm{C}$ catalyst. Kinetics and Catal 56: 84-88.

22 Wu X, Mo J, Li X, Hyder Z, Xiao J (2008) Green chemistry: C-C coupling and asymmetric reduction by innovative catalysis. Prog Nat Sci 18: 639-652.

23 Pandarus V, Ciriminna R, Béland F, Pagliaro M (2011) Selective hydrogenation of functionalized nitroarenes under mild conditions. Catal Sci \& Technol 1: 1616-1623.

24. Kresse G, Hafner J (2000) First-principles study of the adsorption of atomic $\mathrm{H}$ on Ni (111),(100) and (110). Surf Sci 459: 287-302.

25 Hochard F, Jobic H, Massardier J, Renouprez AJ (1995) Gas phase hydrogenation of acetonitrile on Raney nickel catalysts: reactive hydrogen. J Mol Catal A: Chem 95: 165-172.

26 Chrisman KR (1988) Hydrogen Effects in Catalysis. Fundamentals and Practical Applications 3-55.

7 Ertl G (1989) Z Phys Chemie (BRD) 164: 1115.

28 Bartholomew CH (1990) Hydrogen adsorption on supported cobalt, iron, and nickel. Catal Lett 7: 27-51.

29 Paal Z, Menon PG (1988) Hydrogen effects in organic hydrogenations. Hydrogen effects in catalysis: fundumentals and practical applications 18: 512 .

30 Temkin ON (2001) Sorovskii educational journal 6: 31 (in Russian).

31 Popova NM, Babenkova LV, Savel'eva GA (1979) Adsorption and Interaction of Simplest Gases with Metals of VIII Group.

32 Harrington DA, Norton PP (1988) J Vac Sci and Technol 6: 778.

33 Prozorov DA, Afineevskiy AV, Lukin MV, Ulitin MV (2010) The adsorption heats of hydrogen on the deactivated porous nickel from hydroxide sodium water solution. Izv Vyssh Uchebn Zaved Khim Technol 53: 18-21.

34 Ostrovsky NM (2001) Kinetics of catalyst deactivation: mathematical models and their application. M Science pp: 335.

35 Bartholomew CH (2001) Mechanisms of catalyst deactivation. App Catal A: General 212: 17-60.

36 Lukin MV, Prozorov DA, Ulitin MV, Vdovin YA (2013) Controlled deactivation of a skeletal nickel catalyst with sodium silfide in liquidphase hydrogenation reactions. Kinetics and Catal 54: 412-419.

37 Ulitin MV, Barbov AV, Shalyuhin VG, Gostikin VP (1993) Russ J Appl Chem 66: 497-504. 